Çukurova Üniversitesi Mühendislik Mimarlık Fakültesi Dergisi, 35(3), ss. 797-804, Eylül 2020

\title{
Simenit Gölü Kumunun Seramik Sırlarında Renklendirici Olarak Kullanımının Araştırılması
}

\author{
Didem ÖGE ${ }^{1}$, Ceren PEKŞEN ${ }^{* 2}$ \\ ${ }^{l}$ Ondokuz Mayıs Üniversitesi, Sanat ve Tasarım Anasanat Dall, Lisansüstü Eğitim Enstitüsü, \\ Samsun \\ ${ }^{2}$ Ondokuz Mayıs Üniversitesi, Güzel Sanatlar Fakültesi, Seramik Cam Bölümü, Samsun
}

Geliş tarihi: 21.09 .2020

Kabul tarihi: 23.10 .2020

\section{$\ddot{O} z$}

Seramik bünyeyi ince bir tabaka halinde kaplayan ve camsı yapı oluşturan sırlar, seramik yapıya koruyucu tabaka sağlaması ile birlikte sırın kimyasal bileşimine ve pişirim parametrelerine bağlı ürünün renk, parlaklık ve yüzey pürüzlülüğü gibi özelliklerini etkilemektedir. Seramik sırları için renk önemli bir faktördür. Sırların renklendirilmesi için pigmentlerden, metal oksitlerden veya doğal hammadde kaynaklarından yararlanılmaktadır. Günümüzde seramik teknolojisinin gelişimiyle birlikte doğal kaynak ve atık malzemelerin seramik ve seramik sır hammaddesi olarak kullanımı artmakta ve ticari sır üretiminin yanı sıra doğadan temin edilen malzemelerle alternatif sır kompozisyonları oluşturulmaktadır.

$\mathrm{Bu}$ çalışmada Samsun ili Terme ilçesinde bulunan Simenit Gölü kıyısından temin edilen kumun şeffaf sır kompozisyonunda yeni bir renklendirici kaynağı olarak kullanımı araştırılmıştır. Simenit Gölü Kumu (SGK) öğütme işleminin ardından faz analizi için XRD ve kimyasal kompozisyonunun belirlenmesi için XRF analizlerine tabi tutulmuştur. Termal davranışlarının belirlenmesi için 1sı mikroskobu ve TG/DTA analizleri gerçekleştirilen SGK farklı oranlarda şeffaf sır kompozisyonlarına ilave edilmiş ve seramik bünyelere uygulanmıştır. Farklı oranlarda SGK katkısı ile hazırlanan sırlı bünyelerin pişirimi sonrasında renk analizleri gerçekleştirilmiş ve sarıdan kızıl kahveye renk geçişi gözlemlenmiştir.

Anahtar Kelimeler: Seramik, Seramik sırları, Demir oksit, Simenit Gölü

\section{The Investigation on the Possible Use of Simenit Lake Sand as Colorant in Ceramic Glazes}

\begin{abstract}
The glazes that cover the ceramic body with a thin layer and form a glassy structure, provide protective layer to the ceramic structure and affect the properties such as color, brightness and surface roughness of the product depending on the chemical composition and firing parameters of the glaze. One of the most important factors for ceramic glazes is color. Pigments, metal oxides or natural sources are used for the
\end{abstract}

"Sorumlu yazar (Corresponding author): Ceren PEKȘEN, cpeksen@omu.edu.tr 
coloring of glazes. Nowadays, with the development of technology, the use of natural resources and waste materials as ceramic and glaze raw materials are increasing, and alternative glaze compositions are created with materials obtained from nature as well as the production of commercial glaze.

In this study, the use of sand obtained from the shore of Lake Simenit in Terme District of Samsun province as a new colorant source in transparent glaze was investigated. After grinding process of Simenite Lake Sand (SGK), XRD analysis was performed for phase analysis and XRF was used for determination of chemical composition. In order to determine thermal behavior, heat microscopy and TG/DTA analyses were performed. Then SGK was added to transparent glaze in different proportions and applied on ceramic bodies. Finally, coloring parameters of SGK added glazes were determined and the color transition from yellow to reddish-brown was observed.

Keywords: Ceramic, Ceramic glazes, Iron oxide, Simenit Lake

\section{GíRiș}

Seramik sırları, bünyeyi ince bir tabaka halinde kaplamakta ve camsı bir yapı oluşturmaktadır. Sirlar seramik yapıya koruyucu bir tabaka sağlaması, alkali ve asidik ortamlara karşı direncini arttırması, gözenekli seramik yapıyı mikroorganizmalardan koruması ve yüzey düzgünlüğü sağlamasının yanı sıra ürünün renk, parlaklık ve yüzey pürüzlülüğü gibi nihai özelliklerinin çoğunda büyük bir etkiye sahiptir. $\mathrm{Bu}$ özellikler genellikle sırın kimyasal bileşimine ve pişirim parametrelerine bağlı olarak değişmektedir [1-4].

Seramik sırları için en önemli unsurlardan birisi renktir. Surların renklendirilmesi için pigmentlerden, metal oksitlerden veya doğal hammadde kaynaklarından yararlanılmaktadır. Günümüzde seramik teknolojisinin çok hızlı bir şekilde gelişimiyle birlikte doğal kaynak ve atık malzemelerin seramik ve seramik sir hammaddesi olarak kullanımı hammadde çeşitliliğini arttırmaktadır. Ülkemizde bulunan doğal kaynaklar ve aynı zamanda endüstriyel atıkların kullanımı ile hazırlanan renkli sır kompozisyonlarına yönelik literatürde birçok çalışmaya rastlamak mümkündür. Ticari sır üretiminin yanı sıra doğadan temin edilen malzemelerle alternatif sir reçeteleri oluşturulmakta ve seramik yüzeylere uygulanmaktadır. Birçok doğal katkının sır bünyelerinde renklendirici olarak kullanılabilirliği denenmiş ve olumlu sonuçlar elde edilmiştir [1,5-13].
Bu çalıșmada yüksek miktarda demir oksit içerdiği saptanan Simenit Gölü kumunun sırlarda kullanılabilirliği araştırılmıştır. Demir oksit en yaygın kullanıma sahip doğal pigmentlerden olup, seramik sırlarında önemli ölçüde bir kullanıma sahiptir. Demir oksit hemen hemen bütün geleneksel hammaddelerde farklı miktarlarda bulunabilen en önemli renklendirici oksitlerden biridir. Sır ve bünye rengi üzerinde etkilidir. Fırın atmosferine ve sır bileşimine bağlı olarak sarı ve kırmızıdan kahverengiye, griden siyaha değișen renkler oluşturmaktadır. Ayrıca, seladon, aventurin ve tenmoku gibi özel artistik sırların üretiminde kullanılmaktadır [14-16].

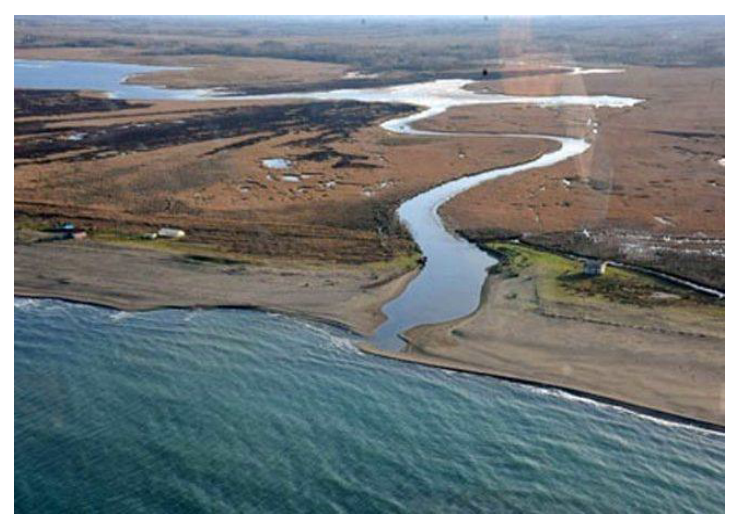

Şekil 1. Simenit gölü

Sir katk1sı olarak kullanılan kum, Samsun ili Terme ilçesinde yer alan Simenit Gölünden temin edilmiştir. Simenit Gölü coğrafi konumu $41^{\circ}$ 15' 59" Kuzey ile $36^{\circ} 57^{\prime} 0^{\prime \prime}$ Doğu GPS koordinatları olup, 41.2667 enlem ve 36.9500 
boylamda bulunmaktadır. Simenit Gölü, Yeşilırmak deltasının doğu kısmında yer alan kıyı set gölüdür (Şekil 1). Gölü denizden ayıran kıyı oku üzerinde 5-6 m yüksekliğinde kumul tepeleri oluşmuştur. $\mathrm{Bu}$ bölgeden temin edilen kum ile yapılan çalışmada ticari sırlara alternatif olarak doğal hammadde katkısı ile seramik bünyelerde düşük sıcaklıklarda olgunlaşan renkli sir kompozisyonunun hazırlanması ve etkilerinin araştırılması amaçlanmıştır.

\section{MATERYAL VE METHOD}

\subsection{Sir Uygulanacak Deneme Plakalarının Hazırlanması}

SGK katkısı ile hazırlanacak farklı sırların farklı bünyelerdeki davranışını incelemek üzere döküm yöntemi ile kırmızı (K), şamotlu (S) ve beyaz vakumlu (B) çamurlardan $25 \times 25 \mathrm{~mm}$ boyutlarında deneme plakaları hazırlanmıştır. Plakalar hava ortamında kurutulduktan sonra elektrikli firında $10^{\circ} \mathrm{C} / \mathrm{dk}$ 1sıtma hızıyla $800{ }^{\circ} \mathrm{C}$ 'de pişirilmiştir (Şekil 2). Pişirim sonrası plakaların faz analizleri X-1şınları difraktometresi (XRD, Rigaku-Rint 2200) ile gerçekleştirilmiştir. XRD analizleri $10-60^{\circ}$ açıları arasında $2^{\circ} \mathrm{dk}$ hız ile çekilmiştir.

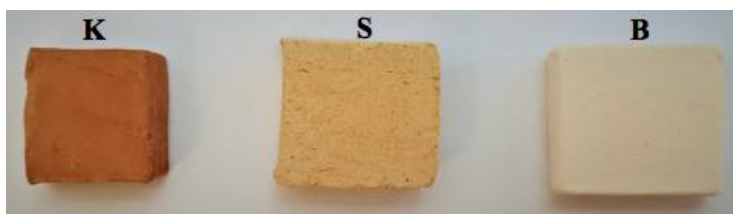

Şekil 2. Kırmızı (K), şamotlu (S) ve beyaz vakumlu (B) çamur ile hazırlanarak pişirilen deneme plakaları

\subsection{SGK Katkılı Sırların Hazırlanması}

Samsun ili Terme ilçesinde yer alan Simenit Gölü kıyısından temin edilen SGK, karakterizasyon işlemleri öncesinde bilyalı değirmeninde 30 dakika süre ile ögütme işlemine tabi tutulmuştur ve $63 \mu \mathrm{m}$ 'lik elek ile elenmiştir. Şekil 3 ile kumun doğal olarak bulunuşu ve öğütme sonrası görüntüsü verilmiştir. (a)

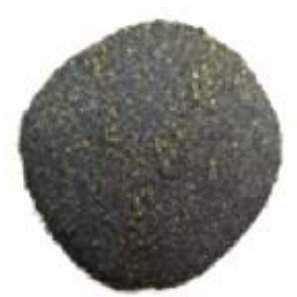

Şekil 3. (a) SGK doğal bulunuşu, (b) öğütme sonrası SGK kumu

SGK'nın faz analizini gerçekleştirmek için XRD kullanılmıştır. XRD analizleri $10-70^{\circ}$ açıları arasında $2 \% \mathrm{dk}$ hız ile çekilmiştir. Kumun kantitatif analizleri X-ışınları floresans (XRF, Rigaku ZSX Primus I) cihazı ile gerçekleştirilmiş ve içerdiği metal oksit oranları belirlenmiştir. SGK'nın termal özelliklerinin belirlenmesi amaci ile 1S1 mikroskobu analizi (Misura, TA Instruments) ve Termogravimetrik-Diferansiyel Termal analizi (STA, 409 PC/PG, Netzsch) yapılmıştır.

Ticari olarak bulunan şeffaf sır kompoziyonuna ağırlıç̧a \%0,5 (S05), \%1 (S1), \%2 (S2), \%3 (S3), $\% 4$ (S4), \%5 (S5) ve \%10 (S10) oranlarında SGK katkısı ile hazırlanan sırlar bilyalı değirmende 30 dakika süre ile ögüutülerek ve deneme plakalarına daldırma yöntemi ile uygulanmıştır. Sırlanmış plakalar $10{ }^{\circ} \mathrm{C} / \mathrm{dk}$ isitma hiziyla $900{ }^{\circ} \mathrm{C}$ 'de tepe sıcaklığına 1 saat bekleme süresi ile kamara tipi elektrikli seramik fırınında pişirilmiştir. Pişirim sonrasinda numunelerin renk analizleri spektrofotometre (CM-2300d, Konica Minolta) ile $360 \mathrm{~nm}-740 \mathrm{~nm}$ dalgaboyu aralığında gerçekleştirilmiştir.

\section{BULGULAR VE TARTIŞMA}

Sır uygulaması yapılacak deneme plakalarının XRD analizi sonuçları Şekil 4'te verilmiştir. Kırmızı çamur bünyede kuvars, hematit ve albit kristalin fazlarını içermektedir. Şamotlu bünyede kuvars ve müllit fazları, beyaz döküm çamuru ile hazırlanmış bünyede ise kuvars, albit ve müllit fazları bulunmaktadır. 


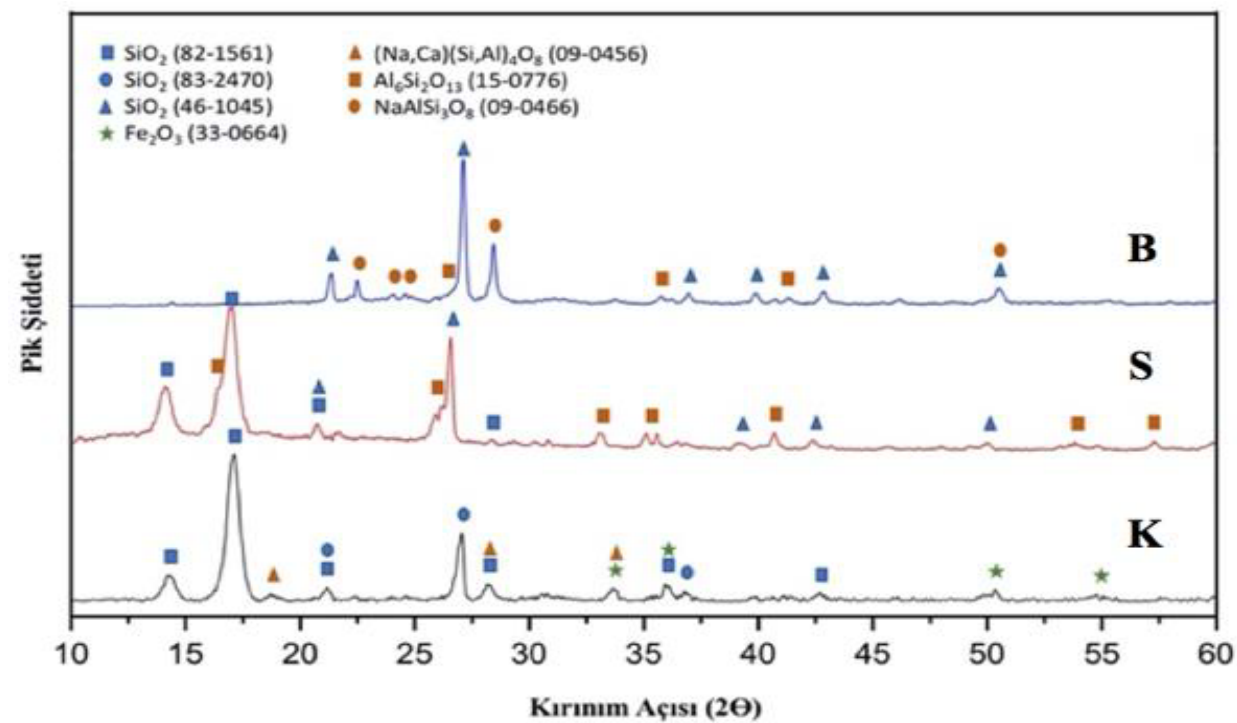

Şekil 4. Isıl işlem görmüş deneme plakalarının XRD grafiği

SGK için $10-70^{\circ}$ açıları arasında $2^{\circ} / \mathrm{dk}$ ile çekilen XRD analizi sonucu elde edilen kırınımlar JCPDS kataloğundaki verilerle karşılaştırılmış ve yapının hematit fazı ve kuvars fazı içerdiği belirlenmiştir (Şekil 5). Kimyasal bileşimi belirlemek için XRF cihazı kullanılmış ve içerdiği metal oksit oranları belirlenmiştir (Çizelge 1). SGK, XRF analizi sonuçlarına göre SGK \%78,3688 oranında demir oksit içermektedir.

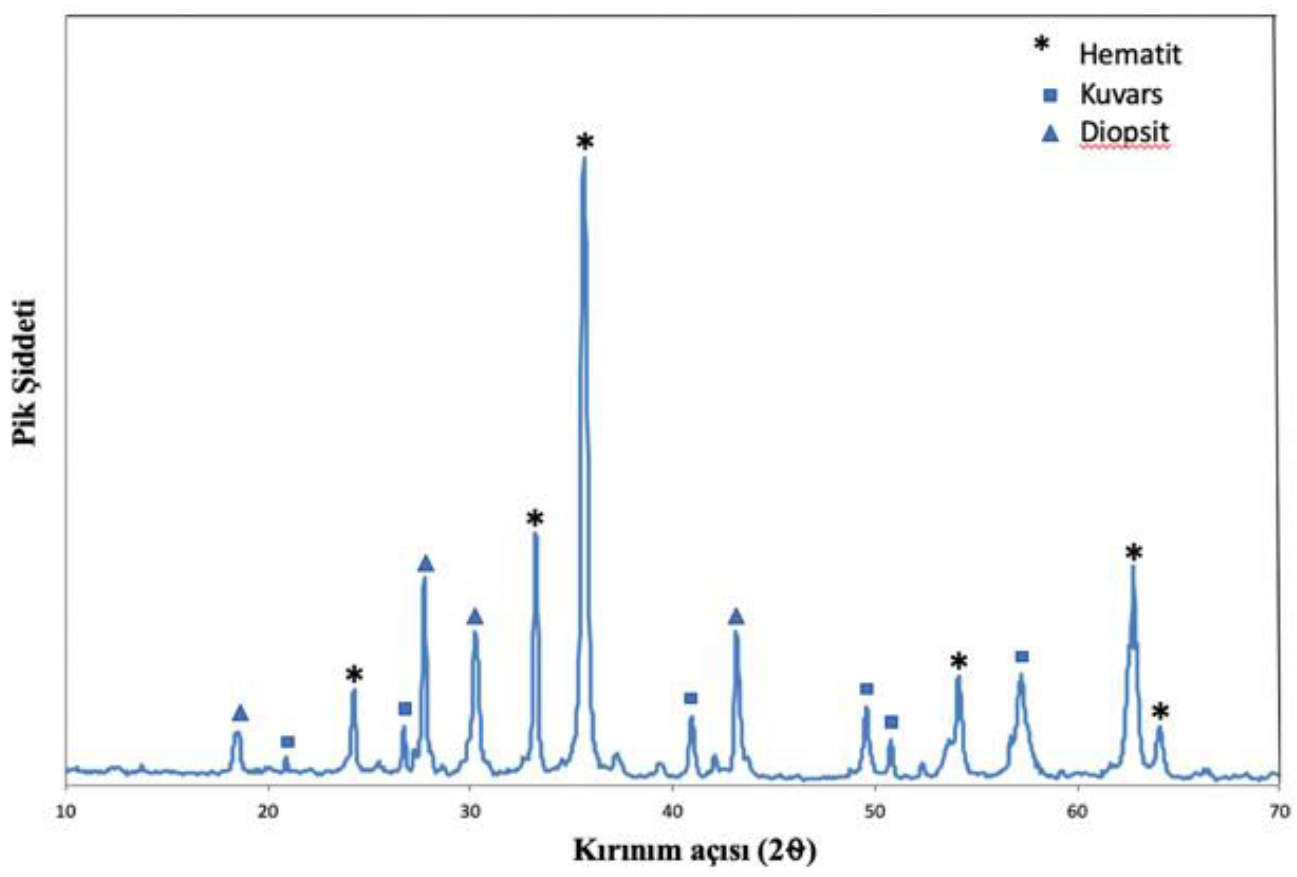

Şekil 5. SGK'nın XRD analizi sonucu 
Çizelge 1. SGK'nın (\% kütlece $)$ kimyasal kompozisyonu

\begin{tabular}{|c|c|}
\hline Oksit & SGK \\
\hline $\mathrm{MgO}$ & 1,6222 \\
\hline $\mathrm{Al}_{2} \mathrm{O}_{3}$ & 3,3769 \\
\hline $\mathrm{SiO}_{2}$ & 5,4573 \\
\hline $\mathrm{P}_{2} \mathrm{O}_{5}$ & 0,1190 \\
\hline $\mathrm{SO}_{3}$ & 0,0337 \\
\hline $\mathrm{K}_{2} \mathrm{O}$ & 0,1040 \\
\hline $\mathrm{CaO}$ & 2,1717 \\
\hline $\mathrm{TiO}_{2}$ & 7,0825 \\
\hline $\mathrm{V}_{2} \mathrm{O}_{5}$ & 0,5804 \\
\hline $\mathrm{MnO}_{\mathrm{Fe}} \mathrm{O}_{3}$ & 0,6376 \\
\hline $\mathrm{ZrO}_{2}$ & 78,3688 \\
\hline $\mathrm{BaO}$ & 0,1042 \\
\hline
\end{tabular}

Isı mikroskobu analizi sonucu ile SGK'nın sinterleme ve yumuşama sıcaklıkları belirlenmiştir (Şekil 6). SGK, $1376{ }^{\circ} \mathrm{C}$ sinterleme sıcaklığına sahipken, yumuşama sıcaklığı $1468{ }^{\circ} \mathrm{C}^{\prime}$ dir. TG-DTA eğrisinde yaklaşık $30{ }^{\circ} \mathrm{C}-1400{ }^{\circ} \mathrm{C}^{\prime}$ ye kadar toplam \%1,98 ağırlık kaybı gözlemlenmiştir. $50{ }^{\circ} \mathrm{C}-200{ }^{\circ} \mathrm{C}$ sıcaklık ağırlığında gözlemlenen başlangıç ağırlık kaybı kum tarafından absorblanan suyun buharlaşmasından kaynaklanmaktadır. TG-DTA eğrisinde keskin bir pik görülmemekle birlikte toplam ağırlık kaybı çok düşüktür (Şekil 7).

SGK katkı oranı \%10 ve altında olarak hazırlanan sır kompozisyonlarının pişirim sonrasında sarıdan kahverengiye bir renk skalasına sahip olduğu

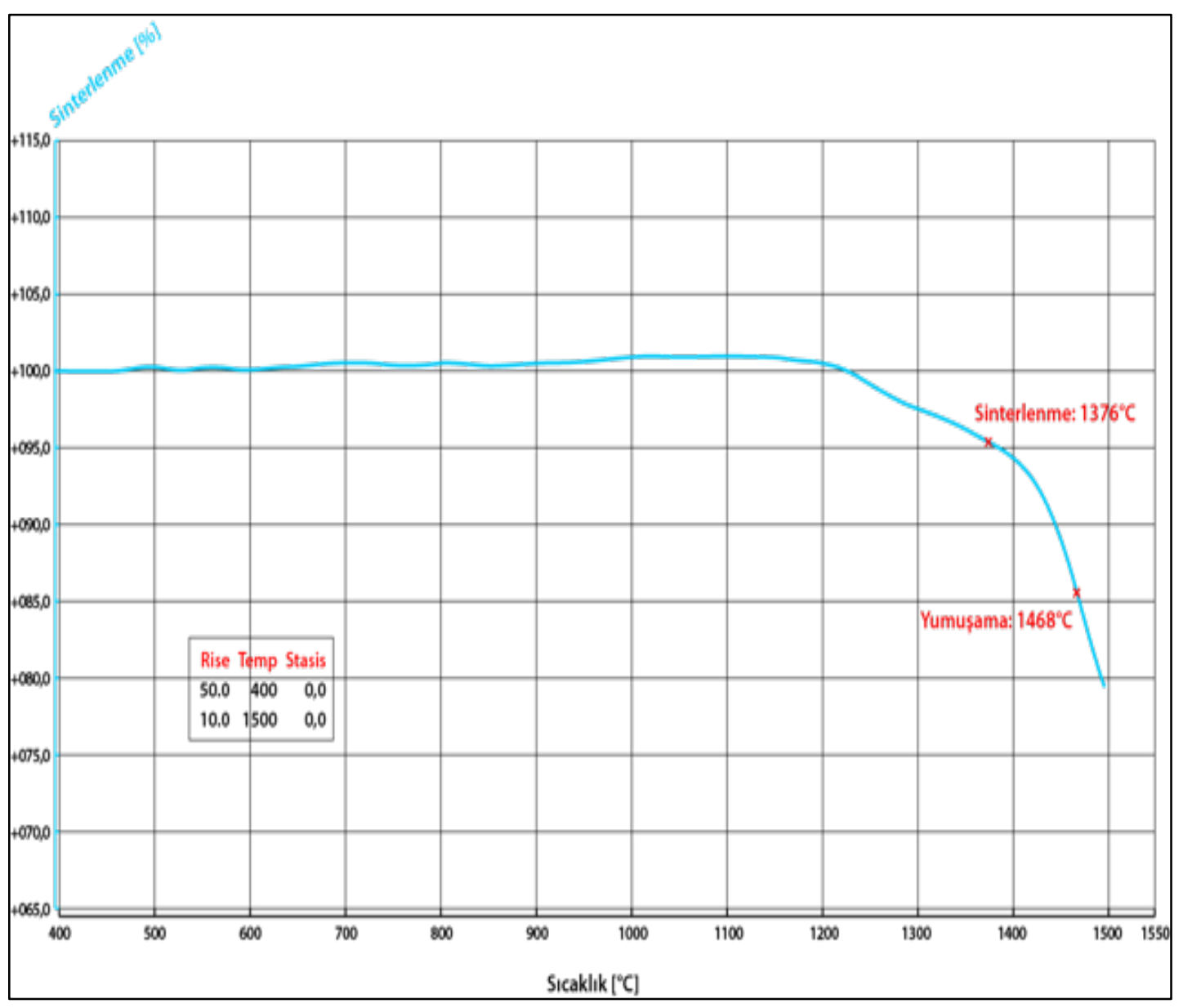

Şekil 6. SGK' nın 1sı mikroskobu analizi grafiği 


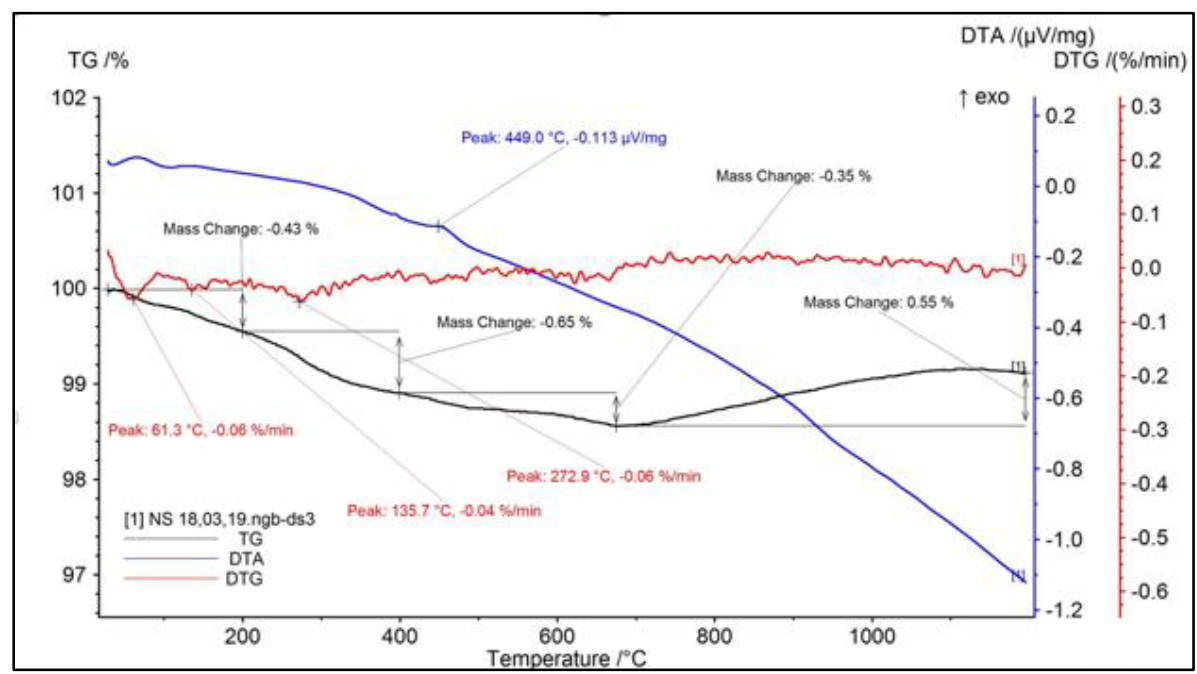

Şekil 7. SGK'nın TG-DTA analizi sonucu

gözlemlenmiştir. SGK katkı oranı \%0,5-\%10 arasında hazırlanan sırların pişirim sonrası dijital görüntüleri Şekil 9 ile verilmektedir.

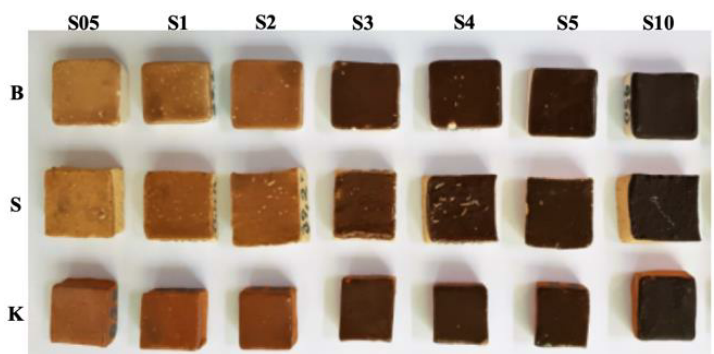

Şekil 9. Ağırlıkça \%0,5-\%10 aralığında değişen oranlarda SGK katkısı ile hazırlanmış sırların sırasıyla beyaz döküm, şamotlu ve kırmızı çamur deneme plakaların pişirim sonras1 görüntüsü

Beyaz döküm çamuru ile hazırlanmış deneme plakaları üzerine uygulanmış \%0,5-\%10 aralığında değişen oranlarda SGK katkılı sırların renk ve parlaklık değerleri Çizelge 2 ile verilmektedir. Rengin açıklık ve koyuluk değeri L*, SGK ilave miktarındaki artış ile düşerken, Kırmızılığı ifade eden $\mathrm{a}^{*}$ ve sarılığ 1 ifade eden $\mathrm{b}^{*}$ değerleri, \%0,5, $\% 1$ ve $\% 2$ katkı oranlarında artmakta iken ilave miktarı arttıkça düşmektedir. Şamotlu çamur ile hazırlanmış deneme plakaları üzerine sırlanmış numunelerin renk ve parlaklık değerlerine göre $\mathrm{L}^{*}$,
SGK ilave miktarındaki artış ile düşmektedir. a* değeri, \%0,5, \%1 ve \%2 katkı oranlarında artmakta iken ilave miktarı arttıkça düşmektedir. $b^{*}$ değerinde ise ilave miktarı arttıkça küçük değer azalması görülmüştür (Çizelge 3). Kırmızı çamur ile hazırlanmış deneme plakaları üzerine sırlanmış sırlarda L* değeri, SGK ilave miktarındaki artış ile düşerken, $\mathrm{a}^{*}$ ve $\mathrm{b}^{*}$ değerleri, $\% 0,5, \% 1$ ve $\% 2$ katk1 oranlarında artmakta iken ilave miktarı arttıkça düşmektedir (Çizelge 4). Parlaklık değerleri incelendiğinde ise tüm deneme plakaları için en yüksek SGK katkı oranına sahip sır kompozisyonlarında en düşük parlaklık değeri gözlemlenmiştir.

Çizelge 2. Beyaz döküm çamur ile hazırlanmış deneme plakaları üzerine uygulanan SGK katkılı sırların renk ve parlaklık değerleri

\begin{tabular}{|c|c|c|c|c|}
\hline $\begin{array}{c}\text { Numune } \\
\text { Kodu }\end{array}$ & $\mathbf{L}^{*}$ & $\mathbf{a}^{*}$ & $\mathbf{b}^{*}$ & $\begin{array}{c}\text { Parlaklık } \\
\mathbf{( 6 0}^{\circ} \mathbf{)}\end{array}$ \\
\hline BT & 85,32 & 4,48 & 9,25 & 38,5 \\
\hline BS05 & 68,09 & 12,21 & 16,2 & 37,8 \\
\hline BS1 & 60,16 & 11,57 & 16,01 & 40,6 \\
\hline BS2 & 56,47 & 12,85 & 15,41 & 53,1 \\
\hline BS3 & 40,51 & 6,89 & 7,13 & 47,2 \\
\hline BS4 & 37,91 & 6,68 & 6,29 & 43,6 \\
\hline BS5 & 35,87 & 6,03 & 5,14 & 34,3 \\
\hline BS10 & 31,46 & 5,45 & 3,33 & 6,3 \\
\hline
\end{tabular}


Çizelge 3. Şamotlu çamur ile hazırlanmış deneme plakaları üzerine uygulanan SGK katkılı sırların renk ve parlaklık değerleri

\begin{tabular}{|c|c|c|c|c|}
\hline $\begin{array}{c}\text { Numune } \\
\text { Kodu }\end{array}$ & $\mathbf{L}^{*}$ & $\mathbf{a}^{*}$ & $\mathbf{b}^{*}$ & $\begin{array}{c}\text { Parlaklık } \\
\left(\mathbf{6 0}^{\circ}\right)\end{array}$ \\
\hline ST & 76,77 & 10,48 & 20,82 & 23,6 \\
\hline SS05 & 65,13 & 13,75 & 18,75 & 27,1 \\
\hline SS1 & 54,22 & 13,43 & 16,26 & 29,5 \\
\hline SS2 & 52,54 & 12,43 & 14,57 & 28,5 \\
\hline SS3 & 40,64 & 7,85 & 8,15 & 24,2 \\
\hline SS4 & 39,19 & 5,92 & 6,15 & 22,4 \\
\hline SS5 & 36,68 & 5,48 & 5,5 & 34,5 \\
\hline SS10 & 31,57 & 5,74 & 3,84 & 4,8 \\
\hline
\end{tabular}

Çizelge 4. Kırmızı çamur ile hazırlanmış deneme plakaları üzerine uygulanan SGK katkılı sırların renk ve parlaklık değerleri

\begin{tabular}{|c|c|c|c|c|}
\hline $\begin{array}{c}\text { Numune } \\
\text { Kodu }\end{array}$ & $\mathbf{L}^{*}$ & $\mathbf{a}^{*}$ & $\mathbf{b}^{*}$ & $\begin{array}{c}\text { Parlaklık } \\
\left(\mathbf{6 0} \mathbf{}^{\circ}\right.\end{array}$ \\
\hline KT & 60,81 & 17,28 & 14,05 & 24,1 \\
\hline KS05 & 56,8 & 15,49 & 14,25 & 36,1 \\
\hline KS1 & 49,92 & 17,31 & 16,11 & 41,6 \\
\hline KS2 & 49,45 & 15,47 & 14,18 & 39,1 \\
\hline KS3 & 40,71 & 8,3 & 8,06 & 38,7 \\
\hline KS4 & 37,72 & 7,04 & 6,93 & 35,5 \\
\hline KS5 & 36,87 & 6,83 & 6,13 & 44,5 \\
\hline KS10 & 31,89 & 5,84 & 3,53 & 7,1 \\
\hline
\end{tabular}

\section{SONUÇLAR}

$\mathrm{Bu}$ çalışmada, ticari şeffaf sır içerisine farklı oranlarda ilave edilen Simenit Gölü kumunun seramik sırlarında alternatif hammadde olarak kullanılabilirliği araştırılmıştır. Yapılan analizler ile SGK'nın yüksek miktarda $\mathrm{Fe}_{2} \mathrm{O}_{3}$ içerdiği saptanmıştır. Farklı oranlarda SGK katkısı ile hazırlanan sır kompozisyonları öncelikle üç farklı seramik bünye yüzeyine uygulanmış ve sırlanmış bünyeler $900^{\circ} \mathrm{C}$ de pişirilmiştir. Pişirim sonrası farklı oranlarda SGK katkısı ile hazırlanan sırlar ile sırlanmış tüm deneme plakalarında sarıdan kızıl kahverengine renk geçişi gözlemlenmiştir. SGK'nın içerdiği yüksek $\mathrm{Fe}_{2} \mathrm{O}_{3}$ nedeniyle rengin açıklık ve koyuluk değerini ifade eden $\mathrm{L}^{*}$ değerinde azalma eğilimi görülmüştür. En yüksek ilave oranına sahip sırlı numunelerde en düşük L* değeri elde edilmiştir. Kırmızılığ 1 ifade eden $a^{*}$ ve sarılığı ifade eden $b^{*}$ değerleri, düşük katkı oranlarında artmakta iken ilave miktarı arttıkça düşmektedir. Tüm sırlanmış deneme plakaları için parlaklık değerleri incelendiğinde ise en yüksek SGK katkı oranına sahip sır kompozisyonlarında en düşük parlaklık değeri gözlemlenmiştir. Sonuç olarak; ticari olarak temin edilen şeffaf sir kompozisyonuna \%0,5-\%10 aralığında değişen oranlarda SGK katkısı ile renkli sır elde etmek mümkün olup hazırlanan sir kompozisyonları farklı seramik bünyelere başarılı bir şekilde uygulanmıştır. SGK katkılı sırlar ile özellikle artistik sır uygulamaları için sarıdan kızıl kahverengi renk geçişleri elde edilmiştir.

\section{KAYNAKLAR}

1. Vandiver, P.B., 1990. Ancient Glazes, Scientific American, 262(4), 106-113.

2. Richerson, D.W., 2012. The Magic of Ceramics, John Wiley \& Sons, Inc., New Jersey.

3. Strecker, K., Costa, H.B., 2014. Formulation of Ceramic Glazes by Recycling Waste Glass, Materials Science Forum, 775-776, 635-641.

4. Silva, R.C, Pianaro, S.A., Tebcherani, S.M., 2012. Preparation and Characterization of Glazes from Combinations of Different Industrial Wastes, Ceramics International, 38, 2725-2731.

5. Kılınç Mirdalı, N., 2017. Inorganic Wastes in Glaze Recipes and Their Effects on Microstructure, Journal of the Australian Ceramic Society, 53(2), 713-718. https://doi.org/10.1007/s41779-017-0084-0.

6. Karasu, B., Çakı, M., Akgün, E., 2002. Seydişehir Alüminyum Tesisi Atığı Kırmızı Çamurdan Üretilen Pigmentlerin Yer ve Duvar Karosu Sirlarında Değerlendirilmesi, 2. Uluslararası Eskişehir Pişmiş Toprak Sempozyumu Bildiriler Kitab1, 138-144.

7. Çakı, M., Karasu, B., 2007. Artvin-Borçka Bölgesi Kırmızı Kilinin Özellikleri, Seramik Çamur ve Astar Üretiminde Kullanımı, SERES IV. Uluslararası katılımlı Seramik, Cam, Emaye, Sir ve Boya Semineri Bildiriler Kitabı, 495- 503.

8. Kılınç Mirdalı, N., Daday, M., Taykurt Daday, M., 2019. Development and Characterization 
of Low Temperature Metallic Glazes in $\mathrm{Na}_{2} \mathrm{O}$ $\mathrm{B}_{2} \mathrm{O}_{3}-\mathrm{SiO}_{2} \quad$ (NBS) System, Ceramics International, 45, 21661-21667.

9. Çetin, S., Kılınç, N., 2004. Tüysüz Köyü Bazaltının Duvar Karosu Sirlarında Kullanım Olanakları Çukurova Üniversitesi Sosyal Bilimler Enstitüsü Dergisi,13, 89-96.

10. Tizgöl, K., Gündeşlioğlu, Ö., 2016. Bir Sera Atığı Olarak Patlıcan Dalı Külünün Düşük Dereceli Seramik Sırlarında Kullanımı, Akdeniz Sanat Dergisi, 9(18), 11-20.

11. Kılınç Mirdalı, N., Halefoğlu, Y.Z., Sakarya, N., 2006. Almanpınarı Kırmız1 Kilinin Seramikte Boya Olarak Kullanılabilirliğinin Araştırılması, Çukurova Üniversitesi Sosyal Bilimler Enstitüsü Dergisi, 15(1), 229-234.

12. Aşkın, A., Kınalı, B., Arkon, O. M., Tatar, İ., 2019. CRT Cam Atıklarının Seramik Sağlık Gereçlerinin Bünye ve Sirlarında Değerlendirilmesi, Yüzüncü Yıl Üniversitesi Fen Bilimleri Enstitüsü Dergisi, 24, 95-101.

13. Taçyıldız, E., 2018. Uçucu Külün Temmoku Sır Özelliklerine Etkileri, Yedi: Sanat, Tasarım ve Bilim Dergisi, 20, 39-44.

14. Ovcacikova, H., VIcek, J., Klarova, M., Topinkova, M., 2017. Metallurgy Dusts as a Pigment for Glazes and Engobes, Ceramics International, 43(10), 7789-7796.

15. Genç, S., Kurt, T., 2017. Etibank Bandırma Boraks Fabrikası Attğının Aventurin Sır Bünyelerinde Alternatif Hammadde Olarak Kullanımı, Art-E Sanat Dergisi, 10(19), 187-202.

16. Pekkan, K., Taşç1, E., Uz, V., 2015. Production of Metallic Glazes and Their Industrial Applications, Journal of The Australian Ceramic Society, 51, 110-115. 